\title{
EAR, NOSE AND THROAT EMERGENCIES AT THE RLI: AUDIT ANALYSIS
}

\author{
TY Linn, SHO; AA Kochhar, Clinical Assistant;
}

JY Osammor, Clinical Assistant; ME Baraka, Consultant ENT Surgeon

Royal Lancaster Infirmary

\section{INTRODUCTION}

The new purpose-built ENT unit at the Royal Lancaster Infirmary (RLI) was opened in February 1996. It is currently a five-day ward, open from Monday 9 am to Friday $5 \mathrm{pm}$. The cover for weekends and bank holidays is provided by the Royal Preston Hospital, twenty miles south of Lancaster. The two consultant ENT surgeons at the RLI share a one in six rota with their colleagues from the Royal Preston Hospital to cover the weekends and bank holidays. The inconvenience caused to patients and their relatives as well as the disruption of continuity of care is yet to be assessed.

The emergency workload of any ENT department is from three sources: in-hospital referrals, referrals from general practitioners and accident \& emergency (A\&E) departments. The latter account for a large proportion of this emergency workload $^{(1)}$. The most common diagnosis necessitating referral is foreign bodies in the aerodigestive tract, followed by epistaxis and some form of ear sepsis ${ }^{(2)}$. Little work has been done, however, with regard to the ENT conditions seen in the A\&E unit.

In our study, we looked at the referrals to the ENT departments at the RLI and the Royal Preston Hospital from the Lancaster A\&E department to determine the pattern of patients' referral and their management.

\section{AIMS}

The aims of the study were threefold:

to look into the number and nature of various ENT conditions seen in the local A\&E department

to study the management of patients presenting with these conditions

- to analyse the number of patients affected by the ENT ward closure at weekends and bank holidays at the RLI.

\section{METHOD}

We studied the casualty records of all patients who presented with ENT conditions to the A\&E unit at the RLI in the six-month period between 5th November 1998 and 4th May 1999. The names were obtained from the main computer in the A\&E unit at the RLI. The following data were obtained:

- name, unit number, age

- time of presentation, ie whether during or out of the Lancaster ENT cover period

- ear, nose, throat or other conditions
- outcome of patients (including referral to the Royal Preston Hospital).

\section{RESULTS}

Two hundred and twenty out of a total of 16347 patients (1.35\%) presented with ENT conditions to the A\&E unit at the RLI within the six-month period. The casualty records of all but two patients presenting with ENT conditions were available for analysis.

Figure 1 represents the age distribution of the patients. There were 176 adults $(81 \%)$ and 42 children (19\%). The majority of cases were of nasal conditions $(44 \%)$. Ear and throat conditions were almost equal at $29 \%$ and $24 \%$ respectively. The other ENT-related conditions such as facial palsy, facial swellings and infections accounted for $3 \%$.

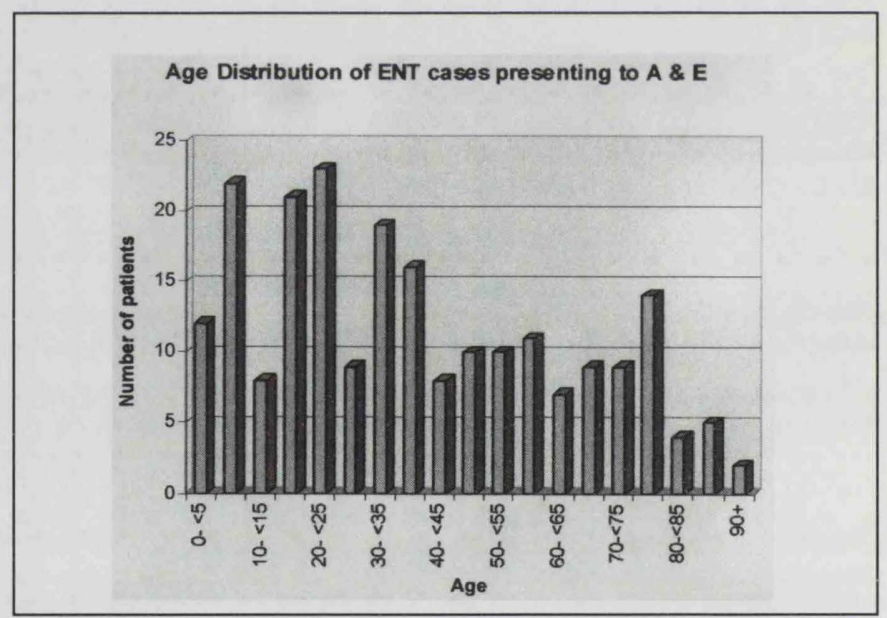

Figure 1 Age distribution of ear, nose and throat conditions presenting to the Royal Lancaster Infirmary A\&E department

Table 1 lists the ENT diagnosis/presenting complaints of all patients recorded by the A\&E doctors. The four commonest ENT conditions were:

1 epistaxis (70 patients)

2 throat conditions in 41 patients; infection (laryngitis, tonsillitis, pharyngitis and quinsy) in 22 patients and foreign bodies in the throat in 19 patients

3 ear sepsis (otitis externa / media) in 38 patients

4 fractured nasal bones in 15 patients.

Others conditions include facial palsy, allergic reactions, hoarseness, salivary glands infections, facial lacerations and earring related problems. 


\begin{tabular}{|llr|}
\hline Bleeding & ear & 2 \\
& nose & 70 \\
Foreign bodies & throat & 3 \\
& ear & 10 \\
& nose & 7 \\
Infections & throat & 19 \\
& ear & 38 \\
Nasal bone fractures & throat & 22 \\
Impacted wax & face & 3 \\
Dysphagia (no foreign body) & & 15 \\
Painful throat (post-op) & & 7 \\
Normal ear & & 2 \\
Swelling (no infection) & ear & 2 \\
& face & 3 \\
Others* & & 2 \\
Total & & 2 \\
*Others include facial palsy, facial lacerations, allergic reactions, \\
salivary gland stones, etc. & & \\
\hline
\end{tabular}

Table 1 ENT conditions by diagnosis/presenting complaints

The management of patients with ENT conditions by the Lancaster A\&E department is illustrated in Table 2. Due to the ENT ward closure at the RLI over the weekends and bank holidays, it is divided into two periods: the Lancaster ENT cover (Monday 9am to Friday 5pm) and the Preston ENT cover (weekends and holidays).

By analysing Table 2, we can see that there is a statistically significant difference in the pattern of management of the patients with ENT conditions by the A\&E department at the RLI during the two periods studied $(\mathrm{P}=0.0074$ which is $<0.05$, two by chi square analysis). Thirty-eight percent were urgently referred to Lancaster as compared to $21 \%$ to Preston. This was statistically significant at $0.10 \%$, chi-square test. In addition, during the Preston cover period, the A\&E department was satisfied with verbal advice more often than during the Lancaster cover period. This could be due to patients' hesitancy to travel to Preston.

\section{DISCUSSION}

In this retrospective study, a total of 220 out of 16346 patients $(1.35 \%)$ presented to the A\&E department at the RLI with ear,

\begin{tabular}{|l|l|l|}
\hline $\begin{array}{l}\text { RLI A\&E staff } \\
\text { decisions }\end{array}$ & $\begin{array}{l}\text { Monday 9am to } \\
\text { Friday 5pm. } \\
\text { (Lancaster cover) }\end{array}$ & $\begin{array}{l}\text { Weekends and } \\
\text { Bank Holidays } \\
\text { (Preston cover) }\end{array}$ \\
\hline $\begin{array}{l}\text { Total number of } \\
\text { patients seen }\end{array}$ & 120 & 98 \\
\hline $\begin{array}{l}\text { Patients treated } \\
\text { and discharged }\end{array}$ & $53(44 \%)$ & $49(50 \%)$ \\
\hline $\begin{array}{l}\text { Urgent referral to } \\
\text { ENT Team }\end{array}$ & $46(38 \%)$ & $21(21 \%)$ \\
\hline $\begin{array}{l}\text { Non urgent referral } \\
\text { to ENT outpatients } \\
\text { at Lancaster }\end{array}$ & $15(13 \%)$ & $18(18 \%)$ \\
\hline $\begin{array}{l}\text { Advice from ENT } \\
\text { team }\end{array}$ & $2(1.7 \%)$ & $7(7 \%)$ \\
\hline Self discharge & $4(3.3 \%)$ & $2(2 \%)$ \\
\hline $\begin{array}{l}\text { Referral to general } \\
\text { surgery team }\end{array}$ & $0(0 \%)$ & $1(1 \%)$ \\
\hline
\end{tabular}

Table 2 Comparison of management of various ENT conditions by the Royal Lancaster Infirmary $A \& E$ doctors nose and throat (ENT) conditions. Ninety-five out of the 218 patients $(44 \%)$ presented with nose-related conditions. Seventy out of these 95 patients presented with epistaxis. Thirty-eight out of the 218 patients $(17 \%)$ presented with ear-related and 22 $(10 \%)$ with throat-related conditions. Approximately $1.35 \%$ of the workload of the A\&E department at the RLI was related to the ear, nose and throat conditions. Of these ENT cases, 19\% were children and $81 \%$ adults. This is different from what was suggested by McShane et al who noted $39 \%$ children and $61 \%$ adults $^{(2)}$.

The common causes necessitating a hospital visit were epistaxis ( 70 cases or $32 \%$ ), followed by throat conditions (41 cases or $19 \%$ ) and ear infection (38 cases or $17 \%$ ). This is in contradiction to the findings of O'Driscoll et al where otitis externa was found to be the commonest cause, followed by ear wax and epistaxis ${ }^{(3)}$.

It is interesting to note that in the very young age group (less than five years) foreign body was the commonest presenting condition ( 7 cases out of 12), whilst in the age group 55 years and over, epistaxis was the commonest presenting conditions (42 cases out of 61).

There are significantly more urgent referrals to Lancaster then to Preston (Table 2). One of the main objectives of the Morecambe Bay Hospitals NHS Trust is to provide excellent health care and services to its population. It is reasonable to suppose that the provision of seven-day ENT service at the RLI would minimise the inconvenience to patients, their relatives, the Lancaster A\&E staff and GPs. Furthermore, it would promote the continuity of care of patients in one hospital. However, one must not forget that resources are limited and the cost-effectiveness of such service provision must be considered carefully.

From our study, it was noted that 21 patients were referred to Preston during the six-month period (which included 26 weekends plus the Christmas and new year bank holidays). This means that about one patient per weekend was referred to Preston from Lancaster. However, referrals from GPs and the A\&E unit of the Westmorland General Hospital during weekends and bank holidays were not included in this study. Also not included in this study are Lancaster inpatients who are not fit for discharge by Friday and who have to be transferred Preston at weekends. The inclusion of all of this data would undoubtedly change the figures. Hence, a larger and multi-departmental study needs to be carried out to determine the exact number of patients who are affected by the closure of ENT services at the RLI over the weekends and bank holidays.

\section{REFERENCES}

1 Bleach NR, Mandy SMH, Williamson PA Emergency workload in otolaryngology Ann Roy Coll Surg Engl 1994;76:335-338

2 McShane DP Analysis of night-time and weekend otolaryngology service Irish J Med Science 1989;158(6): $150-152$

3 O'Driscoll K, Donnelly MJ, McShane DP, Burns H An audit of ENT casualty service at the Royal Victoria Eye and Ear Hospital Irish J Med Science 1993;162(11):462-465

\section{Acknowledgements}

The authors are grateful to Tracy Lawrenson and Judith Shepherd at the Royal Lancaster Infirmary for their help with the study 